\title{
Building Metacognition and Thinking Using a Deliberate Approach
}

\author{
Sheetal Donaldson and Lynn Field \\ Vancouver Community College
}

This article describes the Context Based Learning (CBL) redesign of Nursing courses addressing life transitions, including by implementing group discussion, written concept analysis, group presentations, reflections on thinking and simulation performance, group skills analysis and a final paper. The purpose of the study was to determine how these strategies build metacognition and thinking in the students. Both students and faculty participants agreed the structure of the courses stimulated thinking and metacognition, especially through group discussion of the presentations based on the concept analysis. Students said listening and a safe learning environment helped them think and reflect. However, the larger the group and the more faculty controlled the group, the less thinking developed. This study provides insights into the importance of a safe learning environment, listening, group size and faculty control in the development of thinking and self-reflection in small group CBL format that may be applicable to many disciplines.

Dans cet article, nous examinons la refonte, axée sur l'apprentissage fondé sur le contenu, des cours en soins infirmiers portant sur les transitions de la vie. Cette refonte comprend la mise en place de la discussion de groupe, de l'analyse de concepts à l'écrit, de présentations de groupe, de réflexions sur la pensée et de simulations, d'analyses de compétence en groupe et d'un travail final. L'étude visait à déterminer de quelle manière ces stratégies permettent de bâtir des capacités de pensée et de métacognition chez les étudiants. Les participants à l'etude, qu'ils soient étudiants ou enseignants, ont reconnu que la structure des cours avait eu pour effet de mobiliser la pensée et la métacognition, tout particulièrement lors des discussions de groupe portant sur les présentations fondées sur l'analyse des concepts. Les étudiants ont dit que l'écoute ainsi qu'un milieu d'apprentissage sûr les ont aidés à penser et à réfléchir. Toutefois, plus le nombre d'étudiants était élevé et plus les enseignants exerçaient un contrôle sur le groupe, moins la pensée trouvait à s'épanouir. Notre étude permet de mesurer l'importance d'un milieu d'apprentissage sûr, de l'écoute, de la taille du groupe et du contrôle exercé par l'enseignant dans le développement de la pensée et de l'autoréflexion dans le contexte de l'apprentissage fondé sur le contenu en petits groupes. Ces résultats pourraient s'appliquer à beaucoup d'autres disciplines.

\section{Background}

$\prod_{\text {Program at Vancouver Community College }}^{\text {he Bachelor of Science in Nursing }}$ (VCC) is an eight-semester program with 24 credits of English, Social Science and Biology courses required before entrance. The program admits 24 students each term. There are 34 courses including 14 nursing clinical experiences incorporated throughout the program. There are six three-credit nursing courses called "Life Transitions" to be completed within the first six semesters of the program. Initially, these were structured using lectures, content-based exams and a final paper. However, a three-year program evaluation and feedback from clinical faculty noted that students struggled to make and communicate clinical judgments based on sound reasoning, apply nursing concepts in their nursing practice, and reflect on their nursing practice. The 
research by Turkle (2015) echoed program concerns. Turkle described the current post-secondary students' difficulty to engage in deep thinking, their lack of patience with struggle, their sense of unease with grey areas, their challenges in communicating relevant information verbally and their difficulty engaging in self-reflection.

Self-regulated learning strategies build both cognitive and metacognitive skills as students develop a reliable discipline-specific knowledge base ((Brookfield, 2012; Kuiper, 2005; Kuiper \& Pesut, 2004; Schön, 1987). Deep thinking, struggle, patience and discussion are required to develop metacognition and self-reflection. The more complex the context, the more self-reflection is required to understand it (Schön, 1987). Metacognition has two components: what we know about our thinking (Schraw \& Graham, 1997) and how we use this knowledge to control or regulate our thinking (Silver, 2013). Several instructional strategies develop metacognition through direct instruction of self-reflection, teacher modeling, small group discussion, and written selfreflection (Brookfield, 2012; Schön, 1987; Schraw \& Graham, 1997).

The authors, both nursing faculty with experience teaching the "Life Transitions" courses, redesigned them with understandings of the importance of thinking and metacognition in nursing practice, and the belief that knowledge is selfdirected, constructed, and contextual. The instruction style in all six courses was changed to a style that requires active student involvement in the learning process. Students must build knowledge as they engage with course concepts, challenge previous approaches to learning and struggle to establish new relationships between concepts. Cases were incorporated into the courses because they build on the ability to think and reason in clinical practice and they allow students to learn professional practice in low-risk situations (Schön, 1987).

\section{The Courses}

Context Based Learning (CBL) is based on the principles of Problem Based Learning (PBL)
(Barrows, 1988) and Cooperative Learning (Johnson, Johnson \& Holubec, 1988). Students engage with course content working in groups of 8-12 with one faculty member around a table in a classroom to discuss nursing concepts as they apply to patients from the case and nursing practice in general. The class is three hours long and runs for 10-12 weeks. The complexity of the courses increases gradually through the program.

Each course outline identifies the nursing concepts and the research articles students must read before each class. Each week, half the students in the group choose an article to analyze then post their analysis on a common web page the evening before the class. They present to their group using a concept map to facilitate peer learning and they apply the concept to the clinical case and their nursing practice. Another student in the group reads the posted analysis and asks questions of the presenter to clarify the analysis and application.

Students assign and rotate group roles each week and develop the agenda at the start of each class. The facilitator enacts the agenda, encourages everyone to participate equally, and addresses disagreement in the group. This is a challenging role which may require co-facilitation in earlier terms. The recorder documents group decisions. The timer monitors time assigned to each agenda item. The summarizer outlines the discussion, assumptions, hypotheses and decisions of the previous week at the start of the class. The class is a cell-phone free zone unless students use phones to record a simulation. This avoids distraction and allows students to focus on the discussion (Turkle, 2015).

CBL differs from traditional tutorial sessions because students follow a structure that includes exploring the research, articulating issues and assumptions, evaluating personal and peer performance in discussions, establishing positive social interdependence and being accountable to the group. The intent is to share power among participants, including faculty.

Students use cooperative and interpersonal skills each class. A list of skills required each term (Appendix A) directs students to consider 
appropriate skills. Classes terminate with students sharing their thoughts on their use of these skills during the class and getting verbal feedback from the group. Verbal feedback helps students develop metacognition (Barrows, 1988). Through weekly exposure to feedback, students gain ease with public evaluation and recognize the value in learning from others' performance (Johnson, Johnson \& Holubec, 1988).

At least twice each course students engage in a simulation experience with actors playing the role of the patient in the clinical case discussed in the course. These actors are briefed prior to the simulation so they adhere to the characteristics of the case. After the simulation, students verbally evaluate their interactions with the patient (with faculty support) then write an analysis of their participation using a prescribed tool.

Assignments are evaluated for marks. The reflection on their simulation interactions is one assignment. At least twice a term, students submit a written concept analysis for marks. The template (Appendix B) asks for concept definition and key ideas, application to the case and application to nursing practice. Instructors use a marking rubric (Appendix C) to evaluate the analysis. Twice a term, students write in-class analyses of their understanding of a concept and its application to the case. There are questions to answer and a marking rubric is provided. Each student evaluates their performance on group skills and faculty provide each student with feedback. At the end of the course, students write a paper that analyses the health of one person in the case and predicts their health outcomes three months in the future using the concepts from the course. A marking rubric is also provided for this assignment.

\section{Faculty Role}

The faculty member's role in CBL is complex. During presentations, questioning, and discussion, faculty keep students focused by asking questions about the presentations and questions and models metacognitive thinking (Barrows, 1988). However, they cannot monopolize the discussion or present information when students' understanding of concepts is inaccurate or application to the case is incomplete (Barrows, 1988). Instead, they clarify thinking, question conclusions and push for application to varying contexts. Faculty members invite students to consider multiple perspectives raised during the discussion and then work to resolve the relationships among the various perspectives to achieve new meanings.

Faculty members demonstrate concept analysis in the early terms of the program by naming the concepts involved, using conceptual language, and applying the concept to their clinical or life experiences. They provide written feedback on the accuracy, clarity and comprehensiveness of the written concept analyses and the clarity of written self-reflections. They give verbal feedback on the presentation of concepts to the group, interactions during simulations and individual group skills. In addition, open discussion of performance normalizes feedback and encourages students to learn from the performance of others.

\section{Methods}

The authors designed this study to gain an understanding of how the CBL strategies impact students' abilities to think and self-reflect (metacognition) and how faculty implement the teaching strategies to build thinking and selfreflection in students. We hoped to better understand the teaching strategies and the process of thinking and metacognition development in the students. The study achieved approval from the college Research Ethics Board and confidentiality and storage of data complied with requirements.

One author recruited a purposeful sample of students in the fall of 2018. Students who had completed five of the six "Life Transitions" courses were invited (via email) to participate, as their experience of the strategies was likely the best of the students in the program. Vancouver Community College is a small urban college whose students come from multiple ethnic communities and whose ages range from 19 - 50 years. Of the 16 students eligible 
to participate, nine did so. English was not the first language for two of the participants.

The other author invited faculty who had taught at least one CBL course to participate. Unfortunately, vacations and turnover restricted the number of faculty available. Of the 12 faculty members eligible, six faculty participated. All but one faculty had nursing experience of more than 15 years and all had a range of nursing experience from general medical surgical to mental health and public health. Four had taught BScN students for at least ten years and had taught the CBL courses at least four times. Four had a Masters degree in education or nursing, one had a BSN degree and the other had an education Doctorate. Half of the faculty interviewed were over 55 years with the youngest being between 35 and 39 years. All were fluent in English.

There were two focus groups for students and faculty. There was an interview guide developed with set open-ended questions. For example, the first interview asked students how the CBL experience helped develop their ability to self-reflect and think, which strategies were particularly helpful, and barriers to thinking and reflection. The first interview with faculty asked how they implemented the CBL strategies, which ones were particularly helpful or hindered thinking and self-reflection, and what other strategies they used to facilitate thinking and selfreflection. The author led the tape-recorded interviews with the student focus group and both authors participated in the tape-recorded faculty focus groups.

Because we used a social constructivist perspective and these were group interviews, the authors assumed participants developed their understandings as the discussion progressed (Silverman, 2014). The interviewer asked the set question then invited participation, clarified responses and asked for additional insights. The authors started analysing the group transcripts by carefully considering one section and then adding larger and larger sections to modify the analysis as per Silverman's (2014) comparison method. Single comments were not discarded as outliers; they were clarified in the second focus group. The authors shared and clarified the analysis of the first focus group transcript in a second interview with each group to further increase the validity of the analysis and seek further insights (Silverman, 2014).

\section{Findings}

All students talked about how the courses helped them think about nursing concepts, cases and clinical practice. They found the concept analyses useful because they had to look for relevant information while reading and connect it to the case in the course. They sometimes found it difficult to apply concepts to cases, but they used personal or clinical experiences to help understand the relevance of the concepts in nursing. They talked about challenging personal assumptions and considering alternate perspectives to expand their thinking. Several found taking the patient's perspective a useful way to challenge their thinking. One student found the final paper especially useful in developing thinking because she needed to anticipate patient outcomes based on evidence from the case and application of course concepts.

All students said class discussion stimulated thinking, so their understanding of concepts evolved through the program. When faculty challenged students' assumptions and perspectives, it enhanced their thinking. When faculty shared personal clinical challenges, students realized restricted thinking could lead to poor clinical decisions. It reminded them to assess the completeness of their thinking when they made decisions.

Students noted two aspects of the CBL courses that decreased engagement and thinking. All students agreed when there were more than eight students in the group, engagement and thinking decreased because there were more presentations to fit into the class so discussion of each presentation was limited. With additional presentations, students felt challenged to absorb and process more information, they became less engaged and stopped listening and thinking as clearly. Faculty control of the group also decreased engagement and thinking 
because students became afraid to ask for clarification and express ideas when faculty dominated discussion. All students agreed that they constantly evaluated their thinking. They talked about the impact of course strategies and the changes to their thinking, particularly challenging their assumptions and expanding their perspectives. All said, they like talking about their reflections but do not find the written reflections useful because they are too prescriptive.

All faculty said the courses simulate thinking and self-reflection and group discussion is important to achieve this. Both students and faculty said listening is an important aspect of thinking and selfreflection. Students found it challenging to read the articles and manage personal feelings surrounding certain subjects, to develop strategies to understand new concepts, to understand the need for repetition of concepts and to develop ease with having their thinking evaluated in a group setting. They stated that the environment in the classroom negatively affected their engagement and reflection on their thinking processes.

\section{Safe Learning Environment}

Each group described safety differently. Most students talked about being open minded, letting participants use their contributions as appropriate as there are many perspectives that help in understanding a concept or case. They talked about being sensitive to emotionally loaded issues and allowing others space to speak or stay quiet. They said body language of participants that indicates boredom or distraction affects their confidence and thus their thinking. "It made [them] fearful to participate and resentful to listen to others." They challenged participants carefully "on the off chance that they can't answer questions. I don't want their grades to suffer and it generates animosity."

Students differed in their view of discomfort in the CBL group. Most agreed that talking in the group and presenting in front of the group was uncomfortable at first, but with experience it became more comfortable. Some English first language and both English second language students sometimes had trouble finding the appropriate language to explain concepts and relationships to the case and their practice. Some students tended to hold back and listen when they were uncomfortable while others pushed forward and spoke to clarify their understanding. Some said discomfort caused them to tune out.

Most faculty said it was their primary responsibility to ensure students felt safe in the CBL classes. This meant they had to be present mentally and emotionally and demonstrate full attention verbally and nonverbally. "I'm usually trying to keep my mind blank so I can listen. If I try to generate questions while someone is talking then I'm not really engaged". "When they see that I'm actively listening to them, not doing anything but actually listening to them, I find that they feel safe to share things that you would never expect them to share." Another faculty member invited all students to participate. She said, "What also helps with the safe environment is ... that what we discuss remains confidential". One faculty spoke at length of how she saw her role as that of a cheerleader and not an instructor.

"I built safety in my group by not being the teacher, but by being the cheerleader and also letting them take over the whole group process. I think this lets them feel like the groups their group, it is not my group. It is not like a classroom. They govern the group. So that provides a safe environment for them".

These faculty were participants; thus, developing meaning was a collective process.

All faculty recognized student self-absorption and anxiety interfered with their ability to listen and engage. Some faculty began each session with a check-in to address outstanding issues or concerns. This airing of tension was necessary before thinking could take place. Other faculty gave frequent reminders of the challenging nature of the $\mathrm{CBL}$ process. "I know this is foreign, I know this is difficult, I know this doesn't make sense, but trust me.... trust the process and we'll get there." "You know, learning is not easy, this is very challenging... But this is how nurses have to think." This was particularly helpful at the start of the program as 
students were unfamiliar and uncomfortable with the CBL process. All faculty noted student anxiety and self-absorption dissipated as they developed trust in the CBL process. "And to be honest, I think the discomfort lessens with more positive feedback (as opposed to constructive criticism) you give them". Giving and receiving feedback in the group was uncomfortable for students. Their inclination is to give only positive feedback. When faculty modeled giving constructive feedback, invited feedback on own performance and ended with personal strengths, it helped normalize the process.

Some faculty actively engaged in creating discomfort to stimulate deeper thinking while others felt less at ease doing so. "I use narratives from my own practice that actually defies some of their assumptions... that will sort of challenge their ideas." The challenge for those who created the discomfort was to ensure the level was not overwhelming as to create anxiety that inhibited learning. "I personally think that you have to be uncomfortable to be learning. You've got to feel that discomfort to be thinking of new perspectives or new ways of analysis." As faculty, "you have to make a judgement for each student about how much is enough stress." These faculty explicitly acknowledged the discomfort explaining it was a natural part of learning, explored the nature of the discomfort, invited students to rise to the challenge by setting high standards, or consciously refrained from rescuing when students were struggling to increase their understanding of a concept.

\section{Listening}

All students said their ability to listen was essential to develop their thinking and self-reflection. Listening to how their classmates explained concepts and applied them to clinical practice and their lives helped students better understand concepts and provided different perspectives. It challenged their assumptions by providing an opportunity to compare and contrast personal views and engage critically with their own thinking. "When you ... listen to another person's perspective of the same thing, it broadens your lens." It also "makes you understand the person a little more." Listening includes attention to body language "so you also get their messages." Some said, "When I'm hearing myself saying it, I understand it even more." However, students cautioned that for those with pre-existing mental health issues, engaging in deep self-reflection could be destructive to one's mental health.

All faculty stated their role was to listen and "if you are doing it well you are tired at the end of the class". True listening requires not thinking or being preoccupied with one's own thoughts. "I'm usually trying to keep my mind blank so I can listen. If I try to generate questions while someone is talking, I'm not really engaged." Faculty demonstrate listening by nodding, maintaining eye contact, asking questions, paraphrasing and seeking clarification, subtly taking notes, letting students do the talking and not looking for a gap in the discussion to interject their thoughts. One faculty stopped taking notes because she found it interfered with her ability to listen.

To gauge how well students were grasping course content, faculty members listened to how students applied concepts in other contexts both personal and professional, asked and answered questions, incorporated complexity into analysis, explained concepts in their own words using correct technical language, explained the relationship between multiple concepts, and described limitations of a concept.

"Usually their own experience or their own family or they bring their own perspective... let's me know they are thinking about that concept and how it's applicable to a patient or family. Beyond that, it has to be the questions and the discussion answers they are providing."

One faculty knew when a student had grasped the concept when students showed "compassion for the individuals in the clinical case". In several instances, faculty heard their clinical students acknowledge that the CBL courses allowed them to have the confidence to engage with patients. One student found patient 
teaching in clinical easier because they had discussed it in the "Life Transitions" courses.

\section{Speaking}

Most students said speaking interferes with listening. It prevents them from listening unless they are questioning to get a response to clarify understanding. Most students spoke with a specific purpose in mind. This included an opportunity to share personal thinking, ask about different perspectives, validate their own understanding, clarify confusions, or question classmates. Some students were personally affected by the concepts (loss, grief, addiction and abuse) so they spoke to unload emotions. "It's cathartic like exercise if you let it out." Speaking was more difficult for some students. They said lack of confidence and knowledge affected their ability to speak.

Most students said speaking about selfreflections in the group provides different perspectives which leads to further self-reflection. There was an opportunity to check self-criticism with the group, balancing it with positive feedback from peers.

All students described effective faculty as being good listeners, being flexible with deadlines, sharing clinical experiences to provide additional perspectives and creating an open learning environment where all feel valued. Ineffective faculty were unable to listen and were overly controlling of the group discussion. They dominated discussion and exhibited their power through favoritism, being argumentative, and highlighting that they were not being part of the group. This prevented sharing of perspectives during discussion. Faculty talked at length about how important it was to know when to engage in discussion.

"I think if you are up there and all you're doing is speaking, you've changed the dynamic of the class because now it's you and them. So for me, I try to allow everyone to share their experience first and then if time permits or when I feel that something would add to what we are

discussing, then I'll add my piece."

To facilitate deeper thinking they asked questions to clarify understandings, challenged application of theory in different contexts, questioned assumptions, posed questions that required linking of concepts from previous classes, modified the clinical case by adding different variables and shared relevant personal and clinical experiences. They also refocused the group when discussion was too social or tangential. One faculty allowed tangential discussions to continue as an important insight would eventually emerge.

Faculty cautioned that talking too much detracted from student participation as the students began to look to faculty for the source of knowledge and assume the faculty's interpretation of the case was the best so their impressions were not valid. "I don't want the class to rely on me and my experience... I'll speak to carry on a concept or to clarify." In addition, they argued that when occupied with speaking they lost the ability to listen and observe the non-verbal dynamics of the group, including individual student anxieties that could have a negative impact on the learning environment. They challenged student thinking very carefully because it had the potential of compromising the safety of the environment.

"Different students are motivated by different things. The relationship I build with a student is important. If I say... I believe you're capable of doing way better and I'm going to cheer you on... then the commitment becomes partly to this relationship and students feel supported to push the boundaries of their thinking."

\section{Discussion}

Students participated in two focus groups, each one at least one hour long. They talked about their thinking, describing concept analysis, assumptions, and alternate perspectives and perspective taking that 
developed from the written analyses, presentations, discussions and questioning built into the courses. They also engaged in metacognition throughout (Schraw \& Graham, 1997). The diversity of students from different ethnic groups encouraged sharing of different cultural assumptions. They talked about comparing their ideas with those shared in the group and looking for evidence to support conclusions. This helped them think deeply, develop persistence and tolerance of complexity and examine the interrelatedness of concepts. However, the study methods did not identify the level of thinking students achieved in the "Life Transitions" courses or the usefulness of other tutorial methods. As the authors of the study designed the "Life Transitions" courses, the findings may be biased.

\section{Safe Learning Environment}

A safe learning environment that embodied respect and trust was an important foundation to thinking and self-reflection in the CBL format at VCC. The physical nature of the classroom with participants seated around a table created a level of intimacy that was new to students and faculty. The expectation of preparation and participation in each class put students in the spotlight so they felt uncomfortable. The emotionally loaded content and the personal relationships between students added to their discomfort. Students initially coped by accepting a range of conversation from classmates, being tentative to give feedback and being hesitant to question. They feared hurting students or gaining a reputation of being unkind. However, they found listening to peer comments on their own ideas preserved their sense of comfort.

The "Life Transitions" courses had guidelines for classroom behaviour to keep the environment safe. These guidelines included basic etiquette such as being prepared, listening carefully, addressing comments to peers (not faculty), collaborating rather than competing, challenging respectfully, affirming comments made by other students, using names to focus attention and policing their own frequency of involvement. However, these attempts were not helpful initially. The inclusion of cooperative and interpersonal skills and group process (Johnson, Johnson \& Holubec, 1988) also did not help students feel safe. Faculty needed to set the tone for safety by demonstrating tolerance of different opinions and establishing a sense of trust in the group. Faculty members were successful from the students' perspective when they were open to student differences and shared their experiences as one of the group, not as the leader.

Chinn (2001) talks about the damaging effects of hierarchical power. She says this "power over" approach to working in groups imposes one's will on the group and encourages individuals to dominate discussion. "Power over" dynamics alienate participants, promote argument, and prevent all views from being shared, so balancing power in the group is crucial (Chinn, 2001). The balance between having a safe learning environment and creating the right amount of discomfort to facilitate learning was a primary concern for faculty. Knowing how to manage this balance was necessary for thinking and selfreflection. Performing a check-in to address outstanding issues and concerns before the class starts is one strategy that balances power as it brings attention to the group as a whole and allows participants to share situations that might affect participation (Chinn, 2001).

\section{Speaking}

According to Turkle (2015), conversation produces the collaboration required for education, but conversation develops slowly; it requires patience and a focus on "nuance and tone" (p. 35). It allows thinking to develop through the process of speaking and listening (Chinn, 2001; Turkle, 2015). Speaking is the connection between understanding ideas and deeper thinking. Students who speak little are often stuck in their thinking and do not move forward in their development (Ketch, 2005). Remaining silent robs the group of valuable perspectives (Chinn, 2001). Most students are not used to active participation in college courses and for some this expectation is especially challenging. Because the first 
CBL course occurs in the first term of the $\mathrm{BScN}$ Program, the expectation of assertiveness is a program norm. Students know it is required and they gradually gain comfort with assertive participation by the end of the first term. As the terms progress, students become more assertively engaged in the group. Personal experience with a course concept and the need to share allows necessary catharsis so students can move forward with their thinking and self-reflection.

During discussion, students' thinking about text material becomes public (Murphy, Wilkinson, Soter, Hennessey, \& Alexander, 2009). To increase thinking and metacognition, students need to consider complex questions in context, find evidence for opinions, state those opinions clearly, challenge the position of others and respond with counterarguments (Reznitskaya et al., 2009). Students agreed that the CBL format did this.

The CBL courses use peer and faculty modeling of thinking and metacognition to clarify thinking and self-reflection. Medina, Castleberry and Persky (2017) describe this modeling process as cognitive apprenticeship. It is "the process of making expert thinking visible to students and fostering the cognitive and meta-cognitive processes necessary for expertise" (Lyons, McLaughlin, Khanova \& Roth, 2017, p. 723). They go on to say educators need to help learners develop metacognitive control by helping them manage uncertainty, redirect their efforts productively, and preserver when they get frustrated. They do this by modelling metacognitive control and identifying when it is happening in the group (Barrows, 1988). Faculty model limit setting and verbal feedback to help students understand their role as group facilitators. The verbal feedback in the group can be uncomfortable, but it is required to help students evaluate their thinking and metacognition (Barrows, 1988). As the terms progress, faculty modeling and feedback fades as students become more skilled with thinking and cooperative skills (Barrows, 1988).

\section{Listening}

To be effective, listening needs to be included in conversations, including listening to others as well as oneself so self-reflection and empathy for others develops (Turkle, 2015). Active listening means being attentive to what people are saying and verbally checking perceptions of what one heard so there is a chance to clarify (Chinn, 2001). Students strongly agreed with the importance of listening in their development of thinking and self-reflection. It led to a valuing of difference and flexibility in thinking that "led to personal transitions". For both English second language students, listening to peers helped them learn the idioms of the language and become fluent.

The purposeful listening to thoughts and contemplation of feelings, and experiences develops self-reflection (Hacker \& Dunlosky, 2003; Schön, 1987). It helps students gain new knowledge through a process of evaluating performance and understanding gaps in information and thinking (Schön, 1987). It requires them to think about their thinking, choose language that accurately describes and explains experiences and then predict the usefulness of their thinking in the future.

Faculty listening to stimulate thinking and self-reflection is not a passive process. It includes hearing words, noting non-verbal behaviour, considering possible responses and choosing appropriate speech to paraphrase, clarify and challenge student responses (Wasserman, 1985). This was difficult depending on the personal context of faculty members. Students wanted faculty to listen, so the lack of listening caused dissatisfaction with some faculty members.

\section{Implications}

Implications from this study are tentative because of the small sample size of students and faculty members and the single program in which the $\mathrm{CBL}$ format was used.

A safe learning environment was required for the students interviewed to think and self-reflect in the "Life Transitions" courses. Safety for students was about respect and trust in the group and careful 
participation by faculty. Faculty needed to create discomfort cautiously to stimulate learning while continuously attending to student anxiety. The sense of safety was also related to familiarity with the CBL process. Clearly stating the goals, challenges and rewards of CBL regularly throughout the courses should help.

Listening and speaking skills were equally important for stimulating thinking and self-reflection in the "Life Transitions" courses. The courses required students to speak professionally using technical language, nursing knowledge, and concepts. However, they also needed to make listening explicit and help students develop listening skills. The importance of listening could be included in the course outlines and emphasized throughout the courses.

In this study, active listening was the primary role of faculty members in the "Life Transitions" courses. Most faculty are familiar with a more assertively verbal role in the classroom so professional development should be available to help faculty learn to listen and balance power in the group. Students in the study said group size affected their ability to think and self-reflect. If the CBL format continues as outlined, groups larger than eight students should be used cautiously.

\section{Table 1a}

Group Skills Term 1: Prerequisite Group Skills for NURS 1163 (required from the start of the course)

\section{Professional Responsibility \& Accountability}

1. Is punctual

2. Submits research to the group WIKI 24 hours before class starts

3. Apologizes when late.

4. Completes assigned tasks

5. Volunteers to undertake tasks

6. Participates in problem solving and simulations during each session
7. Responds to fair, constructive feedback with acceptance and gratitude (not becoming defensive)

\section{Knowledge Based Practice}

1. Perseveres in locating information

2. Presents clearly

3. Presents current information

4. Uses words that others understand

5. Identifies issues requiring additional information

\section{Client-focused Provision of Service (with the PBL group)}

1. Listens and articulates with appropriate verbal and nonverbal behaviours.

2. Expresses verbal and nonverbal behaviours that demonstrate respect for group members (are not rude, or arrogant, or patronizing).

3. Interrupts appropriately

4. Willingly works with group members, shares resources

\section{Ethical Practice}

1. Applies copyright laws when sharing information with the group

2. Maintains confidentiality of group processes \& content

\section{Table 1b}

Group Skills Term 1: New Group Skills for NURS 1163

\section{Professional Responsibility \& Marks Accountability}

1. Identifies own strengths 2

2. Begins to identify own learning 2 needs

3. Begins to develop learning plans for identified learning needs. 


\section{Knowledge Based Practice}

1. Pronounces and uses technical

2 terms correctly

2. Begins to identify assumptions

3. Identifies how context affects the information presented

4. Begins to imagine alternatives

5. Begins to use new knowledge in problem solving

6. Identifies hypotheses about the context

\section{Client-focused Provision of Service} (with the PBL group)

1. Acknowledges contributions from group members

2. Begins to use open-ended and non-judgmental questions appropriately

3. Begins to give constructive feedback to group members.

\section{Ethical Practice}

1. Makes the simulator the primary concern in providing care

2. Provides care in a manner that preserves and protects simulator dignity

3. Initiates and terminates a relationship with the simulator therapeutically.

4. Uses active listening when engaged with the simulator (paraphrases, clarifies, summarizes and uses empathy).

5. Begins to identify key messages and feelings from the simulators

(c) Vancouver Community College

References for Table $1 a$ and $1 \mathrm{~b}$ :

SA Gesondheid 14(1), Art. \#409, 6 pages. DOI: 10.4102/hsag.v14i1.409

Chaves, J.F., Baker, C.M., Chaves, J.A., \& Fisher, M.L. (2006). Self, Peer, and tutor assessment of MSN

competencies using the PBL evaluator. Journal of Nursing Education 45(1), 25-31.

Walsh, A., \& Neville, A. (2005). Tutorial McBloopers - Program for faculty development. Hamilton, ON: McMaster University.

2

2

2

2

2

2

2

2

2

2

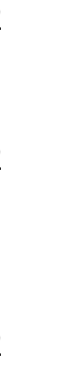

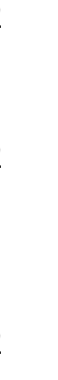

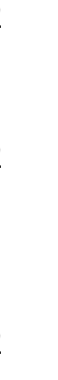

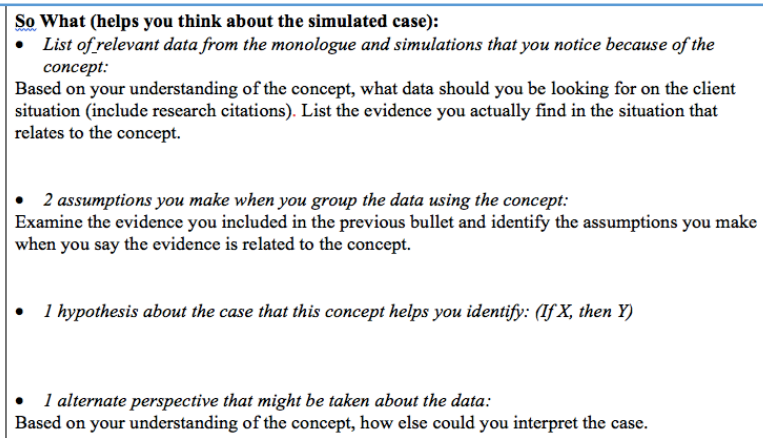

- 2 assumptions you make when you group the data using the concept: 2 assumptions you make when you group the data using the concept:
Examine the evidence you included in the previous bullet and identify the assumptions you make when you say the evidence is related to the concept.

- 1 hypothesis about the case that this concept helps you identify: (If X, then $Y$ )

- 1 alternate perspective that might be taken about the data:

Based on your understanding of the concept, how else could you interpret the case.

Figure $1 b$

Concept Analysis Template Term 2 Cont.

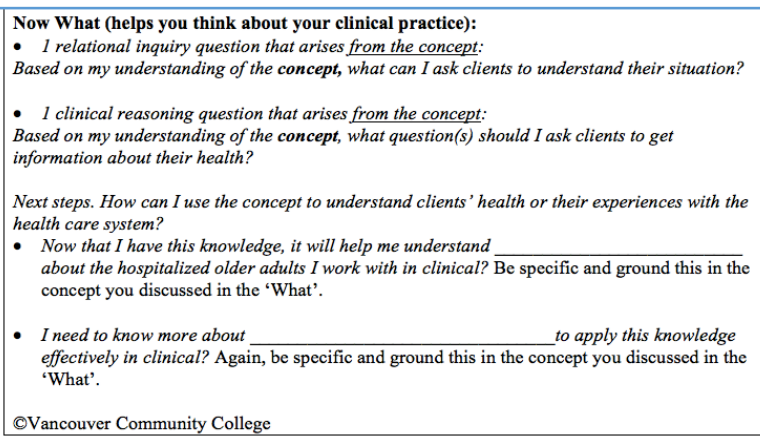

Now that I have this knowledge, it will help me understand about the hospitalized older adults I work with in clinical? $\overline{\text { Be specific and ground this in the }}$ concept you discussed in the 'What'.

- Ineed to know more about to apply this knowledge Ineed to know more about
effectively in clinical? Again, be specific and ground this in the concept you discussed in the 'What'.

OVancouver Community College

Figure 1c

Concept Analysis Template Term 2 Cont. 


\section{Table 2}

\section{Marking Rubric for Research Submission Term 2}

Use of Knowledge

1. Presents current, relevant (to the CBL case) information clearly:

a. Describes concepts only

b. Includes principles

c. Includes research support for the concepts

2. Presents comprehensive information on the topic

a. all key concepts from the reading are included

3. Uses technical terms correctly.

4. Describes how the information is relevant to the case

a. Lists all data relevant to the concept (2)

b. Lists 2 assumptions made when grouping the data according to the concept

c. Lists 1 hypothesis re: the case that arises from the concept

d. Lists 1 alternate perspective that could be taken about the data.

5. Describes how the information will help the CBL group move forward in understanding the case context /older adult population

a. Includes 1 relational inquiry question that arises from the concept

b. Includes 1 clinical reasoning question that arises from the concept

c. Identifies next steps to develop understanding of hospitalized older adults using this concept.

d. Identifies additional questions that need answering to apply this concept effectively in clinical practice.

6. Sources are cited using correct APA format

TOTAL

(C) Vancouver Community College

\section{References}

Chaves, J.F., Baker, C.M., Chaves, J.A., \& Fisher, M.L. (2006). Self, Peer, and tutor assessment of MSN competencies using the PBL evaluator. Journal of Nursing Education 45(1), 25-31.

SA Gesondheid 14(1), Art. \#409, 6 pages. DOI: 10.4102/hsag.v14i1.409

Walsh, A., \& Neville, A. (2005). Tutorial McBloopers Program for faculty development. Hamilton, ON: McMaster University.

\section{Acknowledgements}

The authors would like to acknowledge the valuable participation of students and faculty in the study.

Student participants: Olivia Buchanan, R. R.

Cadlaon, Kayla M. Chavez, Vanessa Gingras, Jessica Mayo, Julia Pavlova, C. Rava, Laketch G. Teshome, $\&$ Eric Tu.

Faculty participants wishing to be acknowledged: Joyce Griffith, RN, BScN, MEd; Hirpal Hundial, $\mathrm{RN}, \mathrm{BScN}, \mathrm{MSN}$; \& Herraj Sandhu, RN, BScN, MSN. 


\section{Biographies}

Sheetal Donaldson is a faculty member in the Bachelor of Science in Nursing Program, School of Health Sciences, Vancouver Community College, Vancouver, British Columbia, Canada.

Lynn Field (retired) was a faculty member in the Bachelor of Science in Nursing Program, School of Health Sciences, Vancouver Community College, Vancouver, British Columbia, Canada. 